\title{
First seeds of X-ray lasers: a tribute to Pierre Jaeglé
}

\section{Annie Klisnick}

Annie Klisnick, "First seeds of X-ray lasers: a tribute to Pierre Jaeglé," Proc. SPIE 11886, International Conference on X-Ray Lasers 2020, 1188603 (8 July 2021); doi: 10.1117/12.2593521

SPIE. Event: XVII International Conference on X-Ray Lasers, 2020, Online Only 


\title{
First seeds of X-ray lasers: a tribute to Pierre Jaeglé
}

\author{
Annie Klisnick \\ Université Paris-Saclay, CNRS, ISMO, 91405 Orsay, France
}

\begin{abstract}
The series of the International Conference on X-ray Lasers was initiated by Pierre Jaeglé in 1986. Pierre passed away in November 2019 at the age of 88 . He is recognized as one of the passionate pioneers of the field of X-ray lasers. In this paper I will remind some of his major scientific achievements, which contributed to the emergence of ultrashort coherent XUV sources generated from intense lasers.
\end{abstract}

Keywords: XUV lasers, XUV spectroscopy

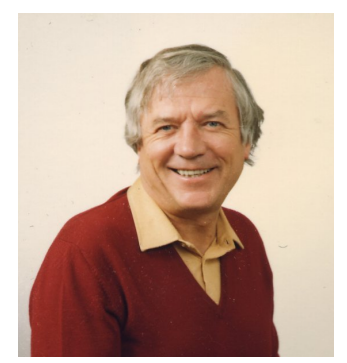

Throughout his rich career as a CNRS scientist, Pierre Jaeglé played a significant role in enabling and promoting the use of XUV/soft-X ray radiation as a powerful tool for scientific investigations. In this paper, which is not meant to be a review on X-ray laser research, I will concentrate on some of Pierre's major scientific achievements, which contributed to the emergence of the XUV spectral range for science, while covering three complementary aspects: the development of instrumentation for spectroscopy, the generation of new laboratory sources based on high-power lasers, and the exploration of original scientific applications of these sources.

In the early 1960's as a young scientist Pierre Jaeglé took part in one of the first pioneering experiments of X-ray absorption spectroscopy using synchrotron radiation at the Frascati laboratory (Italy), where his newly developed soft X-ray spectrometer was implemented ${ }^{1}$. Few years later, in parallel with his work using synchrotron radiation, he started to investigate the XUV emission and absorption properties of plasmas produced by one of the first nanosecond lasers installed in Orsay. Pierre's expertise in XUV spectrometers allowed to obtain emission spectra with high spectral and spatial resolution, which contained several new features, as compared to the spectra obtained from spark discharges that were the usual sources of X-rays available in laboratories at that time. Not only new, still unassigned spectral lines were observed, but also few intensity anomalies. This led Pierre and his co-workers to publish in 1971 the first experimental evidence of an "absorption anomaly" in the XUV spectrum of an aluminium plasma, which was tentatively interpreted as caused by a population inversion ${ }^{2,3}$.

Together with other pioneers (both theoreticians and experimentalists) in the field, Pierre Jaegle then became an active and enthusiastic promoter of the development of X-ray laser research, which was experimentally carried out in the few highpower laser facilities that existed worldwide in the early 80s. At the Laboratoire de Spectroscopie Atomique et Ionique (LSAI, Orsay, France) that he had recently founded, he engaged his research group in the investigation of the recombination pumping scheme in low- $Z$ plasmas, using the $\mathrm{Nd}$ :glass laser installed at Ecole Polytechnique ${ }^{4}$. As a young $\mathrm{PhD}$ student I joined the group in 1982, and I started to study recombination pumping in Li-like ions under the supervision of Pierre.

In 1985 the first demonstration at the Livermore Laboratory (USA) of a strong X-ray laser emission at $20 \mathrm{~nm}$, in a selenium plasma pumped by collisional excitation ${ }^{5}$ led Pierre and his co-worker Alain Sureau to initiate the first international

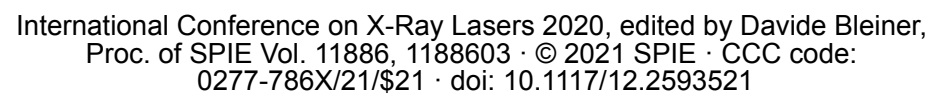


conference on X-ray lasers. Since Pierre was a hiking- and skiing-lover, a passion that he liked to share with his international colleagues and friends, the conference was held in Aussois, a small mountain resort in the French Alps. This meeting $^{6}$ started a series of successful conferences held every two years, where the spectacular progress in the development of plasma-based XUV lasers, as well as of other intense coherent XUV sources has been reported and discussed by the international community for over 3 decades now. Pierre participated to all meetings until the Conference held in Berlin in 2006, during which he was invited to present a talk with his own reminiscences of the early history of X-ray lasers. He explained in particular how he first met Dennis Matthews and Szymon Suckewer in a ski trip in the Rocky Mountains during a conference in $1978^{7}$.

In the 1990's while the field of plasma-based X-ray lasers was blooming worldwide, Pierre was a driving force for his group at LSAI, in engaging new national and international collaborations, in enabling the construction of upgraded experiments, or in encouraging the use of innovative instrumentation, like multilayer XUV optics or electronic detectors were at that time. This led to several important achievements. In 1992 a saturated X-ray laser operated in double-pass amplification was demonstrated in Ne-like germanium ${ }^{8}$, in a collaborative experiment performed at Rutherford Laboratory (UK). In 1994 strong lasing was reported for the first time at the J 0-1 transition in a Ne-like zinc plasma pumped by collisional excitation", contributing to elucidate the so-called "J 0-1 anomaly" 10 .

The zinc X-ray laser was generated in the newly-built 5-beam experimental area (Fig. 1), which was exclusively dedicated to X-ray laser experiments at the LULI $0.5 \mathrm{~kJ}$-laser facility in Ecole Polytechnique (Palaiseau, France). Even though the number of experimental runs that could be carried out in a year was constrained by the rules of shared laser access to the facility, the fact that the X-ray laser generation set-up was permanently installed was a real asset. It significantly facilitated the development in the following years of an ambitious program of application experiments in various fields ${ }^{11,12}$, involving several PhD students under the stimulating leadership of Pierre. All the group members as well as the external French or foreign collaborators most probably remember that the experiments could be performed until late at night, while including excellent group dinners taken in the LULI mezzanine.

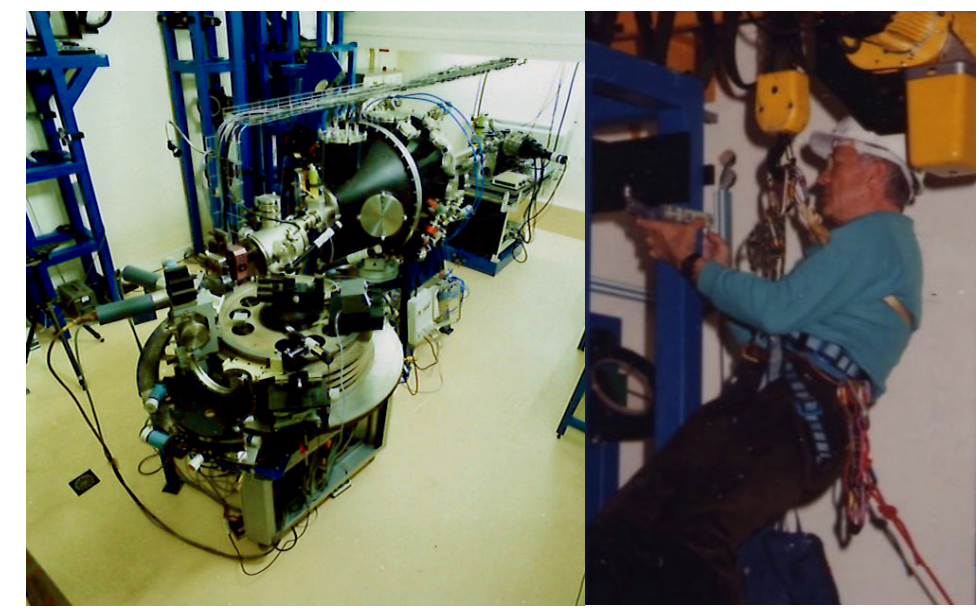

Figure 1. Left: the 5-beam experimental area dedicated to the X-ray laser research program, installed at the LULI $0.5 \mathrm{~kJ}-$ laser facility in Ecole Polytechnique (Palaiseau, France) in 1992. The grating spectrometer originally built by Pierre is shown in front. Right: Pierre is using his alpinism skills to perform careful cleaning of the infrared mirrors that were used to transport the five laser beams to the target chamber.

In the late 1990's to early 2000's, the demonstration of saturated X-ray lasers pumped either in the transient regime ${ }^{13}$ or in optical-field ionized plasmas ${ }^{14}$ using a short pulse CPA laser, opened new prospects to the field, in particular because of their significantly reduced driving energy requirement. Few years later another major breakthrough was reported: the injection-seeded operation of an X-ray laser using high-order harmonics generated from gas ${ }^{15}$. For Pierre these 
achievements were the signs that the field was now mature enough to establish X-ray laser facilities able to provide beamtime to a broader community of users. He greatly inspired and enthusiastically supported the project of building the LASERIX facility ${ }^{16}$, which started to be funded in 2000 , and is now hosted by IJC-Lab at Université Paris-Saclay ${ }^{17}$.

Just as he liked mountain-climbing, Pierre Jaeglé was always trying to look up and anticipate the next step to move forward in his research work, with a strong affinity for unexplored areas. Following his retirement Pierre shared his expertise in the field of intense laser-based XUV sources in a monograph ${ }^{18}$ published in 2006. Together with his colleague and friend Prof. Szymon Suckewer, he then contributed to an extended review paper ${ }^{19}$ on X-ray lasers in 2009.

\section{ACKNOWLEDGEMENTS}

I would like to associate with this paper other former group members who, like me, had the priviledge of working with Pierre and who then embarked through his stimulating influence into the fascinating field of X-ray lasers : Pierre Dhez, Antoine Carillon, Gérard Jamelot, Philippe Zeitoun, Bedrich Rus, Stéphane Sebban, David Ros.

\section{REFERENCES}

[1] Mottana , A. and Marcelli , A., "Fifty years since the first European synchrotron-radiation-derived XAFS spectrum (Frascati, 1963)", J. Synch. Rad. 20, 811-815 (2013).

[2] Jaeglé, P. et al., "Experimental evidence for the possible existence of a stimulated emission in the extreme UV range", Phys. Lett. A, 36, 3, 167 (1971).

[3] Chapline G., Wood L., "X-ray lasers", Physics Today, 28, 6, 40-48 (1975)

[4] Jamelot G. et al., "Amplification of soft-X-ray spontaneous emission in aluminium and magnesium plasmas" J. Phys. B: Atom. Mol. Phys., 18, 4647 (1985)

[5] Matthews D.L. et al., "Demonstration of a soft-X-ray- amplifier", Phys. Rev. Lett., 54, 2, 110-113 (1985)

[6] Proceedings of the $1^{\text {st }}$ International Colloquium on X-ray lasers, J. Phys., 47, C6 (1986)

[7] Jaeglé, P., "Nineteen years of X-ray laser research before the First International XRL Conference in 1986", Xray lasers 2006, Springer Proceedings in Physics, Vol. 115, XXIII-XXX (2007)

[8] Carillon, A., et al., "Saturated and near-diffraction-limited operation of an XUV laser at $23.6 \mathrm{~nm}$ ", Phys. Rev. Lett., 68, 19, 2917-2920 (1992)

[9] Rus, B., et al., "Observation of intense soft-X-ray lasing at the $\mathrm{J}=0$ to $\mathrm{J}=1$ transition in neon-like zinc", JOSA B-Optical Physics, 11, 4, 564-573 (1994)

[10] Goldstein, W.H., et al., "Mechanisms for creating population inversions in Ne-like ions", Phys. Rev. A, 36, 3607 (1987)

[11] Jaeglé, P; Sebban, S; Carillon, A; et al., "Ultraviolet luminescence of CsI and CsCl excited by soft x-ray laser", J. Appl. Sci., 81, 5, 2406-2409 (1997)

[12]Zeitoun, P; Albert, F; Jaegle, P; et al., "Investigation of strong electric-field induced surface phenomena by soft X-UV laser interferometry", Nucl. Instrum. Meth. Phys. Res. A , 416, 1, 189-191 (1998)

[13] Kalachnikov, M.P., Nickles, P. V., et al., "Saturated operation of a transient collisional x-ray laser", Phys. Rev. A, 57, 6, 4778-4783 (1998)

[14] Sebban, S; Haroutunian, R; Balcou, P; et al., "Saturated amplification of a collisionally pumped optical-fieldionization soft X-ray laser at $41.8 \mathrm{~nm}$ ", Phys. Rev. Lett., 86, 14, 3004-3007 (2001)

[15]Zeitoun, P; Faivre, G; Sebban, S; et al., "A high-intensity highly coherent soft X-ray femtosecond laser seeded by a high harmonic beam", Nature, 431, 7007, 426-429 (2004)

[16] Ros, D.; Jamelot, G.; Pittman, M.; et al., "LASERIX : a European versatile high rep-rate facility for applications in the XUV range", [Ultrafast X-Ray Sources and Detectors, Proceedings of SPIE, 6703, 670305 (2007)

[17] Pandey, A.K., Papagiannouli, I., et al., "Towards subpicosecond pulses from solid target plasma based seeded soft X-ray laser", Opt. Expr., 28, 20, 28924-28941 (2020)

[18] Jaeglé, P., "Coherent Sources of XUV Radiation: Soft X-Ray Lasers and High-Order Harmonic Generation", Springer Series in Optical Sciences (2006).

[19] Suckewer, S. \& Jaeglé, P., "X-Ray laser: past, present, and future”, Laser Phys. Lett., 6, 6, 411-436 (2009) 